\title{
The role of additional computed tomography in the decision-making process on the secondary prevention in patients after systemic cerebral thrombolysis
}

\author{
This article was published in the following Dove Press journal: \\ Therapeutics and Clinical Risk Management \\ 23 December 2015 \\ Number of times this article has been viewed
}

\section{Piotr Sobolewski' \\ Grzegorz Kozera² \\ Wiktor Szczuchniak' \\ Walenty M Nyka² \\ 'Department of Neurology and Stroke, Unit of Holy Spirit Specialist Hospital in Sandomierz, Sandomierz, Poland; ' 2 Department of Neurology, Medical University of Gdańsk. Gdańsk, Poland}

Introduction: Patients with ischemic stroke undergoing intravenous (iv)-thrombolysis are routinely controlled with computed tomography on the second day to assess stroke evolution and hemorrhagic transformation (HT). However, the benefits of an additional computed tomography $(\mathrm{aCT})$ performed over the next days after iv-thrombolysis have not been determined.

Methods: We retrospectively screened 287 Caucasian patients with ischemic stroke who were consecutively treated with iv-thrombolysis from 2008 to 2012. The results of computed tomography performed on the second (control computed tomography) and seventh (aCT) day after iv-thrombolysis were compared in 274 patients (95.5\%); 13 subjects (4.5\%), who died before the seventh day from admission were excluded from the analysis.

Results: aCTs revealed a higher incidence of HT than control computed tomographies $(14.2 \% \mathrm{vs}$ $6.6 \% ; P=0.003)$. Patients with HT in aCT showed higher median of National Institutes of Health Stroke Scale score on admission than those without HT (13.0 vs $10.0 ; P=0.01)$ and higher presence of ischemic changes $>1 / 3$ middle cerebral artery territory $(66.7 \%$ vs $35.2 \% ; P<0.01)$. Correlations between presence of HT in aCT and National Institutes of Health Stroke Scale score on admission $\left(\mathrm{r}_{\mathrm{pbi}} 0.15 ; P<0.01\right)$, and the ischemic changes $>1 / 3$ middle cerebral artery (phi=0.03) existed, and the presence of HT in aCT was associated with 3-month mortality (phi=0.03).

Conclusion: aCT after iv-thrombolysis enables higher detection of HT, which is related to higher 3-month mortality. Thus, patients with severe middle cerebral artery infarction may benefit from aCT in the decision-making process on the secondary prophylaxis.

Keywords: ischemic stroke, iv-thrombolysis, computed tomography, hemorrhagic transformation

\section{Introduction}

Plain computed tomography (CT) is commonly used for the initial assessment of stroke patients. ${ }^{1} \mathrm{CT}$ rules out hemorrhage, visualizes the occluding thrombus, and identifies early tissue hypodensity and brain edema. ${ }^{2,3}$ Therefore, CT findings have different implications for intravenous thrombolysis (iv-thrombolysis). ${ }^{4,5}$

Control CT is routinely performed 24-36 hours from the stroke onset for the evaluation of ischemic lesions and hemorrhagic transformation (HT) after iv-thrombolysis. ${ }^{5-7}$ Symptomatic HT is the most feared complication of iv-thrombolysis that is routinely diagnosed by control CT, with a negative prognostic value and important implications for secondary prevention in patients who have suffered a cardio-embolic stroke. ${ }^{8}$ However, it is not clear if the additional CT (aCT) assessment, performed in the next
Correspondence: Piotr Sobolewski Department of Neurology and Stroke, Unit of Holy Spirit Specialist Hospital, 13 Schinzla Street, 27-600 Sandomierz, Poland $\mathrm{Tel}+48608510991$

Fax +48 I5 8330593

Email piotrsobolewski@poczta.onet.pl 
days after iv-thrombolysis, may benefit HT detection and help with the decision making in secondary stroke prevention.

Thus, the aim of our study was to assess the potential benefits of aCT performed on the seventh day after iv-thrombolysis for the diagnosis of HT and to assess its long-term prognostic value.

\section{Materials and methods}

We retrospectively screened the medical records of 287 Caucasian patients with acute ischemic stroke who were consecutively treated with iv-thrombolysis from January 2008 to December 2012 in the Department of Neurology and the Stroke Unit of the Holy Spirit Specialist Hospital in Sandomierz (Poland). We analyzed the demographic, clinical, and radiological data of 274 patients (55.2\% male, aged 41-92 years; mean age $69.7 \pm 11.9$ years) and excluded data of 13 subjects (4.5\%) who died before the seventh day from the admission. The stroke unit provided 24-hour stroke service, 7 days a week, according to the European Stroke Organization criteria with the use of appropriate monitoring and diagnostic facilities. ${ }^{9}$ Acute stroke therapy and secondary prophylaxis were applied according to the current European Stroke Organization guidelines and Polish national regulations. ${ }^{4,5,9-11}$ CT was performed in all patients upon admission to the hospital between 24 and 36 hours (control CT), and on the seventh day after iv-thrombolysis (aCT) with the use of GE Hi Speed; Head 4/2i+10/2i, according to the protocol of thrombolytic treatment applied in our stroke center. Experienced radiologists and stroke physicians evaluated all CT scans. HT rates were assessed according to the European Cooperative Acute Stroke Study II criteria. ${ }^{12}$ All baseline CTs were additionally evaluated according to the Alberta Stroke Program Early CT score. ${ }^{13,14}$ Stroke symptoms were assessed on admission using National Institutes of Health Stroke Scale (NIHSS), and the 90-day stroke outcomes were measured with the modified Rankin scale. ${ }^{15,16}$ A favorable outcome was defined as an modified Rankin scale score $\leq 2$ points. All patients treated with iv-thrombolysis in our stroke units were reported to the Safe Implementation of Thrombolysis in Stroke registry and the Pomeranian Stroke Register., ${ }^{77}$ The ethics committee of Świętokrzyska Medical Chamber approved all data analyses.

\section{Statistical methods}

This study was based on a retrospective data analysis. All statistical analyses were performed with STATISTICA v.9.1, and all continuous variables were tested for normal distribution and equality of variance. Because of the non-normality of the variables, non-parametric Mann-Whitney $U$-tests were used to perform the univariate analysis of the continuous variables. Categorical data were compared using chi-square tests. Single variable correlations with the outcome of interest were performed with use of point-biserial and Phi correlation coefficients.

\section{Results}

From the studied cohort of 274 patients with acute ischemic stroke treated with iv-thrombolysis, 56.6\% were independent (modified Rankin scale 0-2), 17.8\% died, and 15.7\% were diagnosed with HT (4.2\% had a symptomatic intracerebral hemorrhage) after 3 months from the stroke onset.

aCT performed on the seventh day after iv-thrombolysis revealed a higher presence of HT compared to control CT scans performed after 24 hours; symptoms, not significant differences regarding the presence of ischemic changes, were found (Table 1). The HT rate in aCT did not differ between patients on anticoagulants prior to intravenous tissue plasminogen activator therapy and those without prior anticoagulation ( $9.5 \%$ vs $12.7 \% ; P=0.68)$.

The subgroup of patients with HT detected in aCT was characterized by a higher median on the NIHSS assessed on admission, a higher presence of ischemic changes $>1 / 3$ middle cerebral artery (MCA) territory (66.7\% vs $35.2 \%$; $P<0.01)$, and a higher 3 -month mortality rate than patients without HT in the aCT. Median NIHSS score on admission was higher in patients with ischemic changes $>1 / 3$ MCA territory than in those with ischemic changes $>1 / 3$

Table I Radiological findings in CTs performed on the second and seventh day after iv-thrombolysis

\begin{tabular}{|c|c|c|c|}
\hline Variables (n) & $\begin{array}{l}\text { Second day after } \\
\text { iv-thrombolysis } \\
\mathbf{N}=274\end{array}$ & $\begin{array}{l}\text { Seventh day after } \\
\text { iv-thrombolysis } \\
\mathbf{N}=\mathbf{2 7 4}\end{array}$ & $P$-value \\
\hline \multicolumn{4}{|c|}{ Ischemic changes, $\mathrm{n}(\%)$} \\
\hline Abnormal CT & $166(60.6)$ & $187(68.3)$ & 0.07 \\
\hline $\begin{array}{l}<\mathrm{I} / 3 \text { territory } \\
\mathrm{MCA}\end{array}$ & $68(24.8)$ & $75(27.4)$ & 0.40 \\
\hline $\begin{array}{l}>1 / 3 \text { territory } \\
M C A\end{array}$ & $93(33.9)$ & $106(38.7)$ & 0.50 \\
\hline $\begin{array}{l}\text { Posterior } \\
\text { territory }\end{array}$ & $5(1.8)$ & $6(2.2)$ & 0.76 \\
\hline $\mathrm{HT}^{*} \mathrm{n}(\%)$ & $18(6.6)$ & $39(14.2)$ & $<0.01$ \\
\hline HTI & $6(2.2)$ & II (4.0) & 0.22 \\
\hline HT2 & $4(1.5)$ & II (4.0) & 0.07 \\
\hline $\mathrm{PHI}$ & $5(1.8)$ & $12(4.4)$ & 0.09 \\
\hline $\mathrm{PH} 2$ & $2(0.7)$ & $3(1.1)$ & 0.65 \\
\hline PHrI, PHr2 & I (0.4) & $2(0.7)$ & 0.56 \\
\hline
\end{tabular}

Notes: *According to the ECASS II definition. Significant $P$-values are shown in bold. Abbreviations: CT, computed tomography; iv, intravenous; MCA, middle cerebral artery; $\mathrm{HTI}$, hemorrhagic transformation type I; HT2, hemorrhagic transformation type 2; $\mathrm{PHI}$, parenchymal hemorrhage type 1 ; $\mathrm{PH} 2$, parenchymal hemorrhage type 2; $\mathrm{PHrl}$, parenchymal hemorrhage remote type I; $\mathrm{PHr}$, parenchymal hemorrhage remote type 2; ECASS, European Cooperative Acute Stroke Study. 
MCA territory (15 [11-18] vs 9 [7-12] points; $P<0.01)$. No significant differences regarding other clinical and radiological parameters were found; however, hemoglobin levels and median diastolic blood pressures between the second and seventh day from the stroke onset tended to be higher in the subgroup of patients with HT detected in aCT (Table 2).
Correlations tests showed significant associations between baseline NIHSS and the presence of HT in the $\mathrm{aCT}\left(\mathrm{r}_{\mathrm{pbi}}=0.15\right.$; $P<0.01)$ and infarction volume $>1 / 3$ MCA territory and the presence of HT in the aCT (phi=0.03); no significant association between diastolic blood pressure between the second and seventh day and the presence of HT in the aCT $\left(\mathrm{r}_{\mathrm{pbi}}=0.04 ; P=0.52\right)$ was found. Hemoglobin levels tended to

Table 2 The clinical characteristics of the subgroups of patients with and without HT in the additional CT

\begin{tabular}{|c|c|c|c|}
\hline n (\%) & $\begin{array}{l}\text { Patients with } \mathrm{HT}^{*} \text { in the } \\
\text { additional } \mathrm{CT} \\
\mathbf{N}=\mathbf{2} \text { I }\end{array}$ & $\begin{array}{l}\text { Patients without } \mathrm{HT}^{*} \text { in the } \\
\text { additional } \mathrm{CT} \\
\mathrm{N}=253\end{array}$ & $P$-value \\
\hline \multicolumn{4}{|l|}{ Demographic data } \\
\hline Age (years), mean, SD & $71.0 \pm 10.5$ & $69.6 \pm 11.2$ & 0.75 \\
\hline Male sex, n (\%) & II (52.4) & $140(55.3)$ & 0.79 \\
\hline \multicolumn{4}{|l|}{ Logistic factors } \\
\hline Onset to treatment time, median (IQR) & $135(125-165)$ & $160(135-180)$ & 0.11 \\
\hline \multicolumn{4}{|l|}{ Risk factors, n (\%) } \\
\hline Arterial hypertension & $18(85.7)$ & $167(66.0)$ & 0.64 \\
\hline Coronary heart disease & $9(42.9)$ & I44 (56.9) & 0.21 \\
\hline Atrial fibrillation & $8(38.1)$ & $82(32.5)$ & 0.59 \\
\hline Diabetes mellitus & $2(9.5)$ & $42(16.6)$ & 0.40 \\
\hline Dyslipidemia & $18(85.7)$ & $193(76.3)$ & 0.32 \\
\hline Smoking & $4(19.1)$ & $52(20.6)$ & 0.87 \\
\hline Prior stroke & $2(9.5)$ & $43(17.0)$ & 0.37 \\
\hline Antiplatelet therapy before stroke & II (52.4) & 149 (58.9) & 0.56 \\
\hline Anticoagulant therapy before stroke & $2(9.5)$ & $32(12.7)$ & 0.68 \\
\hline \multicolumn{4}{|l|}{ Clinical status } \\
\hline NIHSS on admission (pts), median (IQR) & $13.0(\mid 1.0-18.0)$ & $10.0(7.0-15.0)$ & 0.01 \\
\hline Delta NIHSS first-seventh day (pts), median (IQR) & $6(3.5-10.5)$ & $6(3.0-9.0)$ & 0.54 \\
\hline \multicolumn{4}{|l|}{ Secondary prevention between the } \\
\hline \multicolumn{4}{|l|}{ second and seventh day, $\mathrm{n}(\%)$} \\
\hline Antiplatelet & $7(33.3)$ & $129(60.0)$ & 0.12 \\
\hline Anticoagulant orally & $3(14.3)$ & $16(6.3)$ & 0.17 \\
\hline Antiplatelet + LMWH (prophylactic dose) & II (52.4) & $109(34.1)$ & $0.4 \mathrm{I}$ \\
\hline \multicolumn{4}{|l|}{ Long-term outcome } \\
\hline Unfavorable outcome at 90 days (mRS 3-5) & $7(33.3)$ & $70(26.7)$ & 0.58 \\
\hline Death (mRS 6) & $6(28.6)$ & $21(8.3)$ & $<0.01$ \\
\hline \multicolumn{4}{|l|}{ Blood pressure on admission } \\
\hline MAP (mmHg), median (IQR) & II 3.3 (106.7-123.7) & $106.7(96.7-116.7)$ & 0.55 \\
\hline SBP (mmHg), median (IQR) & $160.0(|46.0-| 7 \mid .0)$ & $152.0(\mid 40.0-170.0)$ & 0.13 \\
\hline $\mathrm{DBP}(\mathrm{mmHg})$, median (IQR) & $89.0(80.0-99.0)$ & $80.0(80.0-90.0)$ & 0.85 \\
\hline \multicolumn{4}{|l|}{ Blood pressure on the first day } \\
\hline MAP $(\mathrm{mmHg})$, median $(\mathrm{IQR})$ & $104.7(96.7-106.7)$ & $103.3(98.3-108.7)$ & 0.82 \\
\hline $\mathrm{SBP}(\mathrm{mmHg})$, median (IQR) & $148.0(\mid 38.0-156.0)$ & $142.0(\mid 35.0-156.0)$ & 0.61 \\
\hline $\mathrm{DBP}(\mathrm{mmHg})$, median (IQR) & $86.0(76.0-88.0)$ & $82.0(80.0-87.0)$ & 0.90 \\
\hline \multirow{2}{*}{\multicolumn{4}{|c|}{$\begin{array}{l}\text { Blood pressure between the second } \\
\text { and seventh day }\end{array}$}} \\
\hline & & & \\
\hline MAP (mmHg), median (IQR) & $101.3(97.3-103.7)$ & $99.3(95.3-102.3)$ & 0.11 \\
\hline SBP (mmHg), median (IQR) & $139.0(\mid 30.0-146.0)$ & $135.0(\mid 30.0-142.0)$ & 0.52 \\
\hline $\mathrm{DBP}(\mathrm{mmHg})$, median (IQR) & $82.0(80.0-86.0)$ & $80.0(77.0-84.0)$ & 0.07 \\
\hline \multicolumn{4}{|l|}{ Laboratory findings before thrombolysis } \\
\hline INR on admission, median (IQR) & $1.05(0.98-1.18)$ & $1.02(0.97-1.10)$ & 0.27 \\
\hline Glucose level (mmol/L), median (IQR) & $6.5(5.4-8.3)$ & $6.4(5.6-7.5)$ & 0.82 \\
\hline Hemoglobin level (g/L), median (IQR) & $14.5(\mid 3.4-15.4)$ & $14.0(13.1-15.0)$ & 0.07 \\
\hline Creatinine level $(\mu \mathrm{mol} / \mathrm{L})$, median (IQR) & $90.3(75.2-101.6)$ & $83.6(69.0-96.9)$ & 0.61 \\
\hline eGFR $\left(\mathrm{mL} / \mathrm{min} / \mathrm{l} .73 \mathrm{~m}^{2}\right)$, median (IQR) & $67.0(64.0-86.0)$ & $75.0(62.0-90.0)$ & 0.44 \\
\hline
\end{tabular}


Table 2 (Continued)

\begin{tabular}{|c|c|c|c|}
\hline n (\%) & $\begin{array}{l}\text { Patients with } \mathrm{HT}^{*} \text { in the } \\
\text { additional CT } \\
2 \text { I }\end{array}$ & $\begin{array}{l}\text { Patients without } \mathrm{HT}^{*} \text { in the } \\
\text { additional CT } \\
253\end{array}$ & P-value \\
\hline \multicolumn{4}{|l|}{ Baseline CT } \\
\hline Old ischemic changes in baseline CT, $n(\%)$ & $9(42.9)$ & $85(33.6)$ & 0.39 \\
\hline Early ischemic changes in baseline CT, n (\%) & $5(23.8)$ & $59(23.3)$ & 0.96 \\
\hline Median ASPECTS score (pts), median (IQR) & $9.0(8.0-10.0)$ & $10.0(8.0-10.0)$ & 0.37 \\
\hline ASPECTS score $\leq 7$ pts, $\mathrm{n}(\%)$ & $29(9.5)$ & $24(9.5)$ & 0.99 \\
\hline \multicolumn{4}{|l|}{ Additional CT } \\
\hline Ischemic changes $<$ I/3 territory MCA, n (\%) & $2(9.5)$ & $24(9.49)$ & 0.99 \\
\hline Ischemic changes $>1 / 3$ territory MCA, $n(\%)$ & $14(66.7)$ & $89(35.2)$ & $<0.01$ \\
\hline Posterior territory stroke, n (\%) & I (4.7) & $5(1.98)$ & 0.40 \\
\hline
\end{tabular}

be associated with the presence of HT in the $\mathrm{aCT}\left(\mathrm{r}_{\mathrm{pbi}}=0.11\right.$; $P=0.07)$. The presence of HT in the aCT was associated with mortality rate at a 3 -month follow-up (phi=0.03).

\section{Discussion}

Our study shows that brain CT performed on the seventh day after iv-thrombolysis may detect significantly more HT than CT routinely performed on the second day after treatment. Our results also show that a higher baseline NIHSS score on admission, presence of ischemic changes $>1 / 3 \mathrm{MCA}$ territory, and higher hemoglobin levels may indicate the benefit from aCT scanning regarding HT detection as the presence of HT detected by aCT is associated with a higher 3-month mortality rate.

A brain CT is routinely performed in the Polish stroke unit during the qualification for iv-thrombolysis and the follow-up between 24 and 36 hours from the therapy., ${ }^{4,5}$ It is highly sensitive in the detection of hemorrhagic complications of iv-thrombolysis; however, some authors show that protocol requiring repeated neuroimaging 24 hours after intravenous tissue plasminogen activator is not supported by clinical practice data and recommend it rather in case of clinical deterioration after iv-thrombolysis. ${ }^{4,5,9,18}$ In our opinion, our findings may justify repeated neuroimaging and show potential benefit from the aCT performed on the seventh day after iv-thrombolysis in patients without clinical deterioration.

Our data show that acute ischemic stroke patients receiving iv-thrombolysis who had a greater initial severity of stroke symptoms according to their NIHSS score and those with ischemic changes $>1 / 3$ MCA territory are at a higher risk of HT presence. Both high NIHSS score on admission and ischemic area $>1 / 3$ MCA territory are well-known predictors of long-term unfavorable outcome and symptomatic intracranial bleeding complications in acute ischemic stroke. ${ }^{13,19-25}$ Our results show that both of them may be also associated with further presence of asymptomatic HT. Thus, we believe that patients with a high NIHSS score on admission and ischemic changes $>1 / 3$ MCA territory may benefit from the implementation of aCT imaging beyond routine procedures. We also notice the potential prognostic value of aCT regarding 3-month mortality.

We also believe that aCT imaging may bring benefit for secondary stroke prevention. Presence of HT may influence the implementation of anticoagulant or antiplatelet therapy; thus, aCT may help with the decision making on its applications. As 38\% of patients with HT in the aCT suffered AF in our cohort, and $9.5 \%$ were on oral anticoagulants before the stroke, aCT results could help in specifying the terms of (dis)continuation of anticoagulation therapy after seventh day from the stroke onset. Our results show that patients with a high NIHSS score on admission and infarction area $>1 / 3$ MCA territory could be considered for aCT before initiation of antithrombotic therapy with oral anticoagulants, which are usually introduced in subacute phase of stroke, but are contraindicated even in asymptomatic bleeding. We believe that this issue emphasizes the practical impact of our study.

The tendency to associate higher hemoglobin levels with the presence of HT is another novel finding, which might be followed-up in future studies. Previous reports mainly showed that a low hemoglobin level on admission predicts short- and long-term outcomes in patients with acute ischemic stroke and is associated with the growth of infarction volume, stroke severity, and outcome. ${ }^{26-30}$ However, it has been also previously reported that erythropoietin combined with tissue 
plasminogen activator may exacerbate tPA-induced brain hemorrhage in rats due to upregulation of matrix metalloproteinase, necrosis factor, and interleukin-1 receptor-associated kinase. ${ }^{31}$ A similar mechanism may potentially explain higher hemoglobin levels in patients with HT in aCT in our cohort; however, we realize that it may be a more complex effect, which needs further clinical and biochemical evaluation.

Our study is a retrospective observation study with a number of limitations. The sample population was narrow in scope, and the results of our study may not apply to patients treated with intra-arterial thrombolysis or endovascular treatment of stroke. ${ }^{32}$ Additionally, the risk profile of the included patients might be lowered by exclusion of patients who died within 7 days from the analysis. Thus, we have to admit that the generalizability of our results performing CT only, without magnetic resonance imaging, can be considered another limitation of our study. Therefore, we find confirmation of our results by other reports with magnetic resonance imaging reasonable.

\section{Conclusion}

Our data may suggest that an aCT performed on the seventh day after iv-thrombolysis is justified in selected patients because it allows additional detection of radiological signs of HT, which are associated with long-term mortality. Especially patients with an MCA infarction $>1 / 3$ MCA territory and severe stroke deficit reflected by a high NIHSS score on admission may be considered for an aCT and may benefit from repeated neuroimaging in decision-making process on secondary prophylaxis with antithrombotic therapy.

\section{Author contributions}

Piotr Sobolewski contributed to the study design, patient selection, clinical work, data collection, analysis, interpretation, and writing of the manuscript. Grzegorz Kozera contributed to the study design, statistical analysis, and data interpretation. Wiktor Szczuchniak contributed to patient selection, clinical work, data collection, statistical analysis, and interpretation. Walenty M Nyka contributed to analysis and interpretation. All authors contributed toward data analysis, drafting and revising the paper and agree to be accountable for all aspects of the work.

\section{Disclosure}

Research activities of G Kozera were funded by the Ministry of Science and Higher Education, Poland, Office of the Governor of Pomerania, Poland; he received speaker's honoraria from the University of Gdańsk, Poland, and received honoraria from Boehringer-Ingelheim for giving lectures. P Sobolewski received honoraria from Boehringer-Ingelheim for giving lectures. W Szczuchniak and WM Nyka report no conflicts of interest in this work.

\section{References}

1. von Kummer R, Bourquain H, Bastianello S, et al. Early prediction of irreversible brain damage after ischemic stroke at CT. Radiology. 2001;219(1):95-100.

2. Dzialowski I, Weber J, Doerfler A, Forsting M, von Kummer R. Brain tissue wateruptake after middle cerebral artery occlusion assessed with CT. J Neuroimaging. 2004;14(1):42-48.

3. Moustafa RR, Baron J-C. Clinical review: Imaging in ischaemic strokeimplications for acute management. Crit Care. 2007;11(5):227.

4. Adams HP, del Zoppo G, Alberts MJ, et al. Guidelines for the early management of adults with ischemic stroke. a guideline from the American Heart Association/American Stroke Association Stroke Council, Clinical Cardiology Council, Cardiovascular Radiology and Intervention Council, and the Atherosclerotic Peripheral Vascular Disease and Quality of Care Outcomes in Research Interdisciplinary Working Groups. The American Academy of Neurology affirms the value of this guideline as an educational tool for neurologists. Circulation. 2007;115(20):e478-e534.

5. Jauch EC, Saver JL, Adams HP, et al; on behalf of the American Heart Association Stroke Council, Council on Cardiovascular Nursing, Council on Peripheral Vascular Disease, and Council on Clinical Cardiology. Guidelines for the Early Management of Patients with Acute Ischemic Stroke: Executive Summary. A Guideline for Healthcare Professionals from the American Heart Association/American Stroke Association. Stroke. 2013;44(3):2-8.

6. Ringleb PA, Bousser MG, Ford G, et al; on behalf of the European Stroke Organization (ESO) Executive Committee and the ESO Writing Committee. Guidelines for Management of Ischaemic Stroke and Transient Ischaemic Attack 2008. Cerebrovasc Dis. 2008;25(5):457-507.

7. Wahlgren N, Ahmed N, Davalos A, et al. Thrombolysis with alteplase for acute ischaemic stroke in the Safe Implementation of Thrombolysis in Stroke-Monitoring Study (SITS-MOST): an observational study. Lancet. 2007;369(9558):275-282.

8. Berger C, Fiorelli M, Steiner T, et al. Hemorrhagic transformation of ischemic brain tissue: asymptomatic or symptomatic? Stroke. 2001; 32(6): 1330-1335.

9. Guidelines for management of ischaemic stroke and transient ischaemic attack 2008. European Stroke Organisation (ESO) Executive Committee; ESO Writing Committee. Cerebrovasc Dis. 2008;25(5):457-507.

10. Postępowanie w udarze mózgu. Wytyczne Grupy Ekspertów Sekcji Chorób Naczyniowych Polskiego Towarzystwa Neurologicznego. Neur Neurochir Pol. 2012;46(supl.1):16-78.

11. Członkowska A, Kobayashi A. Expert Group of the Section of Cerebrovascular Diseases of the Polish Neurological Society. Management of acute stroke - guidelines from the Expert Group of the Section of Cerebrovascular Diseases of the Polish Neurological Society. Update 2013: thrombolysis. Neurol Neurochir Pol. 2013;47(4):303-306.

12. Hacke W, Kaste M, Fieschi C, et al; for the Second European-Australasian Acute Stroke Study Investigators. Randomised double-blind placebocontrolled trial of thrombolytic therapy with intravenous alteplase in acute ischaemic stroke (ECASS II). Lancet. 1998;352(9136):1245-1251.

13. Barber PA, Demchuk AM, Zhang J, Buchan AM. Validity and reliability of a quantitative computed tomography score in predicting outcome of hyperacute stroke before thrombolytic therapy. ASPECTS Study Group. Alberta Stroke Programme Early CT Score. Lancet. 2000;355(9216):1670-1674.

14. Pexman JH, Barber PA, Hill MD, et al. Use of the Alberta Stroke Program Early CT Score (ASPECTS) for assessing CT scans in patients with acute stroke. AJNR Am J Neuroradiol. 2001;22(8):1534-1542.

15. Lyden P, Brott T, Tilley B, et al. Improved reliability of the NIH Stroke Scale using video training. NINDS TPA Stroke Study Group. Stroke. 1994;25(11):2220-2226. 
16. Bonita R, Beaglehole R. Recovery of motor function after stroke. Stroke. 1988;19(12):1497-1500.

17. Kozera G, Chwojnicki K, Gójska-Grymajło A, Gąsecki D, Schminke U, Nyka WM. Pre-hospital delays and Intravenous thrombolysis in urban and rural areas. Acta NeurolScand. 2012;126(3):171-177.

18. Sehgal S, Mehndiratta P, Talahma M, Eisele S, Sila C. Is a routine head CT after IV-tPA therapy medically necessary? Neurology. 2013;80: P03.170

19. Hacke W, Kaste M, Fieschi C, et al. Intravenous thrombolysis with recombinant tissue plasminogen activator for acute hemispheric stroke. The European Cooperative Acute Stroke Study (ECASS). JAMA. 1995;274(13):1017-1025.

20. Wahlgren N, Ahmed N, Erikksson N, et al. Multivariable analysis of outcome predictors and adjustment of main outcome results to baseline data profile in randomized controlled trials: Safe Implementation of Thrombolysis in Stroke Monitoring Study (SITS-MOST). Stroke. 2008;39(12):3316-3322.

21. Mazya M, Egido JA, Ford GA, et al. Predicting the risk of symptomatic intracerebral hemorrhage in ischemic stroke treated with intravenous alteplase. safe implementation of treatments in stroke (SITS) symptomatic intracerebral hemorrhage risk score. Stroke. 2012;43(6): $1524-1531$.

22. Frankel MR, Morgenstern LB, Kwiatkowski T, et al; for the National Institute of Neurological Disorders and Stroke rt-PA Stroke Study Group. Predicting prognosis after stroke. A placebo group analysis from the National Institute of Neurological Disorders and Stroke rt-PA Stroke Trial. Neurology. 2000;55(7):952-959.

23. Tissue plasminogen activator for acute ischemic stroke. The National Institute of Neurological Disorders and Stroke rt-PA Stroke Study Group. N Eng J Med. 1995;333(24):1581-1587.

24. Tanne D, Kasner SE, Demchuk AM, et al. Markers of increased risk of intracerebral hemorrhage after intravenous recombinant tissue plasminogen activator therapy for acute ischemic stroke in clinical practice: the Multicenter rt-PA Stroke Survey. Circulation. 2002;105(14):1679-1685.
25. Cucchiara B, Kasner SE, Tanne D, et al. Factors associated with intracerebral hemorrhage after thrombolytic therapy for ischemic stroke: pooled analysis of placebo data from the Stroke-Acute Ischemic NXY Treatment (SAINT) I and SAINT II Trials. Stroke. 2009;40(9): 3067-3072.

26. Kimberly WT, Wu O, Arsava EM, et al. Lower hemoglobin correlates with larger stroke volumes in acute ischemic stroke. Cerebrovasc Dis Extra. 2011;1(1):44-53.

27. Tanne D, Molshatzki N, Merzeliak O, Tsabari R, Toashi M, Schwammenthal Y. Anemia status, hemoglobin concentration and outcome after acute stroke: a cohort study. BMC Neurology. 2010;10:22.

28. Milionis H, Papavasileiou V, Eskandari A, D'Ambrogio-Remillard S, Ntaios G, Michel P. Anemia on admission predicts short- and long-term outcomes in patients with acute ischemic stroke. Int J Stroke. 2015; 10(2):224-230.

29. Bill O, Zufferey P, Faouzi M, Michel P. Severe stroke: patient profile and predictors of favorable outcome. J Thromb Haemost. 2013;11(1): 92-99.

30. Kellert L, Martin E, Sikora M, et al. Cerebral oxygen transport failure?: decreasing haemoglobin and haematocrit levels after ischaemic stroke predict poor outcome and mortality: Stroke: RelevAnt Impact of haemoGlobin, Haematocrit and Transfusion (STRAIGHT) - an observational study. Stroke. 2011;42(10):2832-2837.

31. Jia L, Chopp M, Zhang L, Lu M, Zhang Z. Erythropoietin in combination of tissue plasminogen activator exacerbates brain hemorrhage when treatment is initiated 6 hours after stroke. Stroke. 2010;41(9): 2071-2076

32. Słowik A. New perspectives for acute stroke treatment: the role of mechanical thrombectomy. Postep Kardiol Inter. 2014;3(37):145-146.
Therapeutics and Clinical Risk Management

\section{Publish your work in this journal}

Therapeutics and Clinical Risk Management is an international, peerreviewed journal of clinical therapeutics and risk management, focusing on concise rapid reporting of clinical studies in all therapeutic areas, outcomes, safety, and programs for the effective, safe, and sustained use of medicines. This journal is indexed on PubMed Central, CAS,

\section{Dovepress}

EMBase, Scopus and the Elsevier Bibliographic databases. The manuscript management system is completely online and includes a very quick and fair peer-review system, which is all easy to use. Visit $\mathrm{http}: / /$ www.dovepress.com/testimonials.php to read real quotes from published authors. 